\title{
Titanium dioxide as a chemo-affinity solid phase in offline phosphopeptide chromatography prior to HPLC-MS/MS analysis
}

\author{
Michael Mazanek ${ }^{1}$, Goran Mituloviæ ${ }^{1}$, Franz Herzog ${ }^{1}$, Christoph Stingl ${ }^{2}$, James RA Hutchins ${ }^{1}$, \\ Jan-Michael Peters ${ }^{1} \&$ Karl Mechtler ${ }^{1}$
}

${ }^{1}$ Research Institute of Molecular Pathology (IMP), Dr Bohr-Gasse 7, A-1030 Vienna, Austria. ${ }^{2}$ Institute of Molecular Biotechnology (IMBA), Dr Bohr-Gasse 3-5, A-1030 Vienna, Austria. M.M. \& G.M. contributed equally to this work. Correspondence should be addressed to K.M. (mechtler@imp.univie.ac.at)

Published online 14 December 2006; corrected online 3 May 2007 (details online); doi:10.1038/nprot.2006.280

\begin{abstract}
We have developed a new offline chromatographic approach for the selective enrichment of phosphorylated peptides that is directly compatible with subsequent analysis by online nano electrospray ionization tandem mass spectrometry. In this technique, a titanium dioxide $\left(\mathrm{TiO}_{2}\right)$-packed pipette tip is used as a phosphopeptide trap that acts as an offline first-dimension separation step in a twodimensional chromatography system. This is followed by online nano reversed-phase high-performance liquid chromatography. Here, we present suitable methods for enrichment, optimized separately for each step: sample loading, washing and elution from the $\mathrm{TiO}_{2}$-filled tips. To increase the trapping selectivity of the $\mathrm{TiO}_{2}$ column, we used the sodium salt of 1-octanesulfonic acid combined with 2,5-dihydroxybenzoic acid as ion-pairing agents and displacers for acidic peptides. These agents also improve the binding of phosphorylated peptides and block the binding of non-phosphorylated ones. This enrichment procedure takes 30 min, followed by a 100-min HPLC program, including washing and an elution gradient.
\end{abstract}

\section{INTRODUCTION}

The majority of biochemical processes are induced and controlled by post-translational modifications on certain proteins. One of the most frequent modifications is phosphorylation of the amino acids - serine, threonine and tyrosine. It is this reversible phosphorylation that regulates the major (or even the majority of) cellular processes, and it has been estimated that almost $30 \%$ of all proteins in mammalian cells are phosphorylated at some point during their expression ${ }^{1,2}$. This alone would be reason enough to invest time and resources in the analysis of phosphopeptides.

Despite the fact that there are so many phosphoproteins in the cell, phosphorylated residues remain at very low concentrations physiologically and are present in substoichiometric quantities. The presence of high-abundance peptides in samples of biological origin makes it necessary to develop an efficient separation and enrichment method for phosphopeptides.

Earlier established methods for phosphorylation site detection relied on Edman degradation of ${ }^{32} \mathrm{P}$-labeled peptides. Edman degradation is a robust and well-established method, but it shows some limitations when analyzing complex samples and cannot fulfill the requirements for sensitive detection of low concentrations of phosphopeptides ${ }^{1-3}$. Besides the additional needed labeling of the phosphate residues, it would take more than a hundred fold in time to chemically treat and analyze a complex sample related to other techniques for sequencing and phosphorylation site mapping.

Identifying phosphorylation sites in different proteins through mass spectrometry (MS) requires a proper pre-separation and enrichment of the phosphopeptides performed online by the HPLC, because of the often highly complex sample composition.

Some phosphopeptide-selective techniques have been developed, such as immobilized metal affinity chromatography (IMAC) $)^{4-6}$ or two-dimensional HPLC systems using strong cation-exchange chromatography (SCX) and reversed-phase (RP) chromatography ${ }^{7-10}$.
IMAC separation uses the affinity of the negatively charged phosphate group in phosphopeptides for positively charged $\mathrm{Fe}^{3+}$ or $\mathrm{Ga}^{3+}$ ions, which are bound on the stationary phase of the separation column. However, not only phosphopeptides but also acidic groups in peptides will form complexes. The result is nonselective binding of many acidic peptides due to a higher complex building constant with metal ions and displacement of phosphorylated peptides from the IMAC column, resulting in the loss of phosphorylated peptides. O-methyl esterification will block acidic groups (carboxylic groups of the peptide) and represents a possible solution for this problem. Ficcaro et al. ${ }^{5}$ described the methylation of phosphopeptides and the resulting decrease in nonspecific binding of acidic peptides to the IMAC column. Esterification neutralizes the majority of carboxylic groups in a peptide backbone, but can also lead to other reactions such as deamidation and methylation of Asn and Gln residues.

One of the methods for enriching phosphopeptides and reducing the complexity of the biological sample is to perform ion-exchange chromatography before HPLC nano electrospray ionization tandem mass spectrometry analysis. SCX proved useful for separating major phosphopeptides within a complex sample ${ }^{7-10}$. During SCX separation, the phosphorylated peptides elute in early fractions at the mobile phase ( $\mathrm{pH} 2.7$ ) owing to the lack of positive charge or a very low positive charge $(+1)$. Most of the remaining tryptic peptides would have a charge of +2 or +3 , and would therefore bind more strongly to the column. However, despite the enrichment achieved, a significant number of non-phosphorylated peptides will also elute in early fractions and present a possible obstacle in later phosphopeptide analysis. Another possibility is to use anion-exchange chromatography and to separate the phosphorylated peptides according to the (negative) charge they bear. Depending on the $\mathrm{pH}$ value of the mobile phase, sample 
PROTOCOL

TABLE 1 | Amino-acid sequence of synthetic phosphopeptides used throughout the experiment.

\begin{tabular}{|c|c|c|c|c|c|}
\hline Name & $M_{r}$ & Sequence & {$[\mathrm{M}-\mathrm{H}]+$} & {$[\mathrm{M}-2 \mathrm{H}]^{++}$} & {$[\mathrm{M}-3 \mathrm{H}]^{+++}$} \\
\hline PP1 & $2,093.8613$ & TASDTDSSYpAIPTAGMSPSR & 2094.86 & 1047.93 & 698.95 \\
\hline .PP10x. & $2,109.8562$ & & 2110.86 & 1055.93 & 704.29 \\
\hline PP2 & $1,758.7938$ & SVENLPEAGITpHEQR & 1759.79 & 880.4 & 587.26 \\
\hline PP4 & $1,343.5871$ & APPDNLPSPGGSpR & 1344.59 & 672.79 & 448.86 \\
\hline PP5 & $1,302.5493$ & LIEDNEYpTAR & 1303.55 & 652.27 & 435.18 \\
\hline NP6 & $1,263.6208$ & APPDNLPSPGGSR & 1264.62 & 632.81 & 422.21 \\
\hline .PP8ox. & $1,947.8245$ & & 1948.82 & 974.91 & 650.27 \\
\hline PP9 & $2,229.9807$ & QLGEPEKSpQDSSPVLSpELK & 2230.98 & 1115.99 & 744.33 \\
\hline PP10 & $2,309.9471$ & QLGEPEKSpQDSpSPVLSpELK & 2310.95 & 1155.97 & 770.98 \\
\hline PP11 & $2,329.1736$ & KFLSpLASNPELLNLPSSpVIK & 2330.17 & 1165.59 & 777.39 \\
\hline PP13 & $2,026.0176$ & THILLFLPKSpVSDYEGK & 2027.02 & 1014.01 & 676.34 \\
\hline GluFib & $1,569.6696$ & EGVNDNEEGFFSAR & 1570.67 & 785.83 & 524.22 \\
\hline
\end{tabular}

Synthetic phosphopeptides were used to set up the method and test the quality of separation system. All peptides were synthesized in-house (Box 1).

complexity and the number of phosphorylated sites, the next step is the specific enrichment of phosphopeptides. Depending on the next separation step, samples containing phosphopeptides must be either desalted or otherwise prepared for the following analysis steps. Failure to perform proper sample treatment can lead to a loss of analytes and false results.

Pinkse et al. ${ }^{12}$ described the use of $\mathrm{TiO}_{2}$ columns for online coupling with the RP separation column. Interaction and binding of non-phosphorylated peptides was observed and a few acidic peptides could also be enriched by this approach.

The previously published method by Larsen et al. ${ }^{11}$ uses 2,5dihydroxybenzoic acid (DHB) to improve trapping of phosphopeptides by using it at high concentrations $\left(\geq 300 \mathrm{mg} \mathrm{ml}^{-1}\right)$. However, in our hands, DHB alone caused high background in MS and ionization suppression at these concentrations, and at lower concentrations it was not able to enhance the trapping of phosphopeptides. Hence, we introduced the sodium salt of 1-octanesulfonic acid (OSA) as an alternative to DHB. OSA proved to be a very useful ion-pairing agent for peptide and protein analysis in RP-chromatography ${ }^{16,17}$. Moreover, the addition of OSA increases the hydrophobic character of the peptides and enables better trapping on the RP trap column in the following chromatographic separation step.

In an offline approach, Larsen et al. ${ }^{11}$ enriched phosphopeptides by using self-packed $\mathrm{TiO}_{2}$ tips, but we decided to use commercially available pre-packed "TopTips" from Glygen, which are pipette tips filled with bare $\mathrm{TiO}_{2}$, spherically formed with a diameter of $5 \mu \mathrm{m}$, because of their easy availability and reproducible packed bed. Additionally, packing columns, even tips, require some experience and very often this step is responsible for poor, inconsistent or irreproducible results.

In comparison to the methods described earlier, no chemical treatment of the sample is necessary and no additional separation or desalting steps prior to HPLC are needed. This lowers the possible sample loss due to chemical reactions, adsorption to the surface of the stationary phase or poor sample handling. In fact, the sample processing described in this paper is very rapid, uncomplicated and straightforward.

However, a slight unselectivity of the $\mathrm{TiO}_{2}$ trap column still remains, even though it is significantly lowered by the use of additives such as $\mathrm{DHB}^{11}$ or, in our case, OSA. When used at high concentrations, DHB produces a higher background in UV chromatograms and MS spectra (data not shown) and needs a high organic wash step ( $\sim 80 \%$ acetonitrile) to be removed from the $\mathrm{TiO}_{2}$ column.

On reviewing the results obtained, a decision was made to combine both agents for loading the sample. This led to improved recovery of phosphopeptides and to the almost complete removal of non-phosphorylated peptides during the loading step.

The elution of trapped phosphopeptides was performed using an ammonium bicarbonate (ABC) elution buffer to which $50 \mathrm{mM}$ ammonium phosphate was added.

To mimic a complex sample and introduce acidic peptides onto the $\mathrm{TiO}_{2}$ column, BSA-derived tryptic peptides were added to a test mix of synthetic peptides. Trypsinized BSA contains several acidic peptides that show a high affinity for $\mathrm{TiO}_{2}$ and thus compete with phosphopeptides for binding to the column. The test mix consists of several phosphopeptides (see Table 1) and also contains two unphosphorylated peptides (NP6 and Glufib) for negative control. Two different methods were used for analysis of test samples and the real biological sample. For test samples containing synthetic phosphorylated peptides and BSA tryptic peptides, short chromatographic gradients were used. For the complex biological sample, a longer chromatographic wash step upon sample loading onto the trap column was programmed before sample separation. We wanted to circumvent possible problems with phosphate buffer used for sample elution and properly desalt the sample before HPLC separation and MS detection. Additionally, two different nano HPLC systems were used in this study: an UltiMate Plus nano HPLC system coupled to a Deca XP mass spectrometer was used to perform the method development and tests, and an UltiMate 3000 nano HPLC system coupled to an LTQ Fourier transform mass spectrometer was used to perform analysis of biological samples. To achieve the best possible MS results, and enhance the fragmentation, a multistage activation (MSA) procedure was used. The typical fragmentation pattern of phosphopeptides is neutral loss (NL) due to the dissociation of phosphoric acid, and only minor fragmentation along the peptide backbone will occur. As the NL of $m / z 49$ (doubly charged ion) and $m / z 32$ (triply charged 
ion) is not sufficient for successful identification of phosphorylated peptides, further fragmentation of the peptide backbone is induced. This happens through further fragmentation of the expected NL masses after the initial CAD event on the precursor ion. This technique is named MSA and is described by Schroeder and Zumwalt $^{20,21}$. Using the MSA method on the Fourier transform ion cyclotron resonance mass spectrometer enables both the measurement of precursor masses with accuracy in the low ppm range and the production of phosphopeptide-derived $\mathrm{MS}^{2}$ spectra containing fragments not normally produced until the $\mathrm{MS}^{3}$ stage by conventional methods.

The anaphase-promoting complex (APC), purified from HeLa cells, is used to demonstrate the utility of this method for analyzing a complex biological sample. However, this method can be used for trapping and separation of phosphorylated peptides of any origin.

\section{MATERIALS}

\section{REAGENTS}

- Acetic acid (AA) 100\% Suprapur, Merck

- Acetonitrile (ACN) (HPLC grade), Merck

- Ammonia $25 \%$ p.A., Merck

- ABC Ultra, Fluka

- Formic acid (FA) 98-100\% Suprapur, Merck

- OSA, Sigma, p.A., Aldrich

-DHB Part-No. \# 201346, Bruker, Bremen, Germany

- $o$-Phosphoric acid $85 \%$ puriss, Riedel-de-Haën

- Trifluoroacetic acid (TFA), Pierce

- Trypsin Gold was purchased from Promega

- DL-Dithiothreitol (DTT) and iodoacetic acid (IAA) were purchased from Sigma

- Cdc27 peptide antibodies crosslinked to Affi-Prep protein A beads (Bio-Rad,

Hercules)

- Phosphorylated amino acids used for the synthesis of phosphopeptides were purchased from Novabiochem

- Non-phosphorylated amino acids for the synthesis of phosphopeptides were purchased from MultiSynTech GmbH

- Bovine serum albumin (minimum 99\%) was purchased from Sigma

- Synthetic phosphorylated and non-phosphorylated peptides (Table 1,

Box 1) IP buffer: $20 \mathrm{mM}$ Tris- $\mathrm{HCl}$, pH 7.5, $400 \mathrm{mM} \mathrm{NaCl}, 0.01 \%$ Tween,

$20 \mathrm{mM} \beta$-glycerophosphate, $5 \%$ glycerol, $5 \mathrm{mM}$ EDTA, $1 \mathrm{mM} \mathrm{NaF}$,

$0.5 \mathrm{mM}$ DTT,

$0.2 \mathrm{mM} \mathrm{Na}_{3} \mathrm{VO}_{4}, 1 \mu \mathrm{m}$ okadaic acid

- IP buffer without detergent is the same as above but lacks $0.01 \%$ Tween 330

nM nocodazole (Sigma-Aldrich) in DMSO (Fluka)
-PBS (140 mM NaCl, $2.5 \mathrm{mM} \mathrm{KCl,} 10 \mathrm{mM} \mathrm{Na} 2 \mathrm{HPO}_{4}, 1.4 \mathrm{mM} \mathrm{KH_{2 }} \mathrm{PO}_{4}$, $\mathrm{pH} 7.4)$

-TBS-T 0.01 buffer (20 mM Tris-HCl, pH 7.5, $150 \mathrm{mM} \mathrm{NaCl}, 0.01 \%$

Tween)

-TBS (20 mM Tris-HCl, pH 7.5, $150 \mathrm{mM} \mathrm{NaCl}$ )

- $100 \mathrm{mM}$ glycine- $\mathrm{HCl}, \mathrm{pH} 2.2$

$\cdot 1.5$ M Tris-HCl, $\mathrm{pH} 9.2$

- Load solution: AA 20\%; octanesulfonic acid sodium salt $300 \mathrm{mM}$, DHB $20 \mathrm{mg} \mathrm{ml}^{-1}$

-Wash solution: $70 \%$ water; $30 \% \mathrm{ACN}$

EQUIPMENT

- 145-mm tissue culture dishes (Greiner bio-one, Frickenhausen)

- Biofuge (Heraeus)

- Potter-Elvejhem glass-Teflon homogenizer (Wheaton Scientific Products)

- Beckman Optima MAX Ultracentrifuge using a Beckman TLA 45 rotor

(Beckman Coulter)

- $\mathrm{TiO}_{2}$-filled tips: TopTips, produced by Glygen, purchased from SunChrom (purchase order number 668-TT2TIO.96)

REAGENT SETUP

Extraction buffer $20 \mathrm{mM}$ Tris- $\mathrm{HCl}, \mathrm{pH} 7.5,150 \mathrm{mM} \mathrm{NaCl}, 20 \mathrm{mM}$ $\beta$-glycerophosphate, $5 \mathrm{mM} \mathrm{MgCl}, 1 \mathrm{mM} \mathrm{NaF}, 1 \mu \mathrm{M}$ okadaic acid, $1 \mathrm{mM} \mathrm{DTT}$, $0.2 \%$ NP-40, $10 \%$ glycerol, $10 \mu \mathrm{g} \mathrm{ml}^{-1}$ each of chymostatin, leupeptin and pepstatin A (Sigma-Aldrich)

Elution buffer for $\mathrm{TiO}_{2}$ TopTips $\mathrm{ABC}$ buffer $(\mathrm{pH} 10.5 ; 125 \mathrm{mM}$ ) with ammonium phosphate $50 \mathrm{mM}$. Dissolve $0.5 \mathrm{~g} \mathrm{ABC}$ in $\sim 35 \mathrm{ml}$ water and add ammonia solution to reach a basic $\mathrm{pH}$. Then, add $140 \mu \mathrm{l}$ phosphoric acid and adjust $\mathrm{pH}$ with ammonia solution and water to

\section{BOX 1 | PREPARATION OF SYNTHETIC PEPTIDES.}

All synthetic phosphorylated and non-phosphorylated peptides were synthesized in-house using standard Fmoc solid-phase chemistry on an ABI 433A (Applied Biosystems) peptide synthesizer and purified on a BioCAD (Applied Biosystems) preparative C18 RP-HPLC system. The quality of the synthesis was tested by MALDI mass spectroscopy analysis. The steps of this procedure are listed below.

Inject protected amino acids (MultiSynTech $\mathrm{GmbH}$ ) in reverse order at the concentration of $1 \mathrm{mM}$ each, as synthesis takes place from the C-terminal to the N-terminal end. The first amino acid is already bound to the TCP-resin (Pepchem, Goldammer \& Clausen).

$250 \mathrm{mg}$ resin of substitution grade $\left(0.5 \mathrm{mmol} \mathrm{g}^{-1}\right)$ is used for the entire synthesis. The peptide synthesis is monitored by conductivity measurement. All coupling steps are performed automatically by using the programmed routine "FastMoc $0.10 \Omega$ MonPrevPk" supplied with the instrument.

Release and deprotect the completed peptide by treating the resin with $11 \mathrm{ml}$ of $90 \%$ TFA $(\mathrm{v} / \mathrm{v}), 5 \%$ triethylsilane $(\mathrm{v} / \mathrm{v}), 5 \% \mathrm{H} 20$ for $2-3 \mathrm{~h}$. Isolate the peptide by rinsing and filtering the resin (MultySynTech $\mathrm{GmbH}$ ) with TFA.

Precipitate the peptide by adding it dropwise to a $35 \mathrm{ml}$ solution of cold $60 \%$-butyl-methylether $(\mathrm{v} / \mathrm{v})$ and $40 \%$ heptane $(\mathrm{v} / \mathrm{v})$. Store for 60 $\min$ at $-80{ }^{\circ} \mathrm{C}$.

Collect the precipitate by centrifugation and wash three times with $40 \mathrm{ml} t$-butyl-methylether. Lyophilize the peptide under vacuum.

Dissolve the peptide in $5 \mathrm{ml}$ of $0.1 \%(\mathrm{v} / \mathrm{v})$ TFA in water. Inject into an HPLC machine (Vision, Applied Biosystems) and purify by reverse-phase chromatography on a C18 column (Phenomenex, Luna 5C18 or Phenomenex Jupiter 5C18) using a 45 min, 2-45\% gradient of water $+0.1 \%$ TFA to acetonitrile $+0.1 \%$ TFA. The positive fractions are identified by mass spectroscopy in linear and reflector mode (Bruker Reflex III MALDITOF).

Freeze the peptide at $-80^{\circ} \mathrm{C}$ and lyophilize for 2 days.

During the synthesis of phosphopeptides, some oxidations at Met can occur and these oxidized peptides sometimes display a higher abundance than the non-oxidized starting peptides. The introduction of oxidized peptides was not anticipated during the synthesis; however, it occurs to some extent for two peptides described, PP1 and PP8. These peptides show a different chromatographic behavior and are clearly separated from their non-oxidized counterparts. 
TABLE 2 | Settings used for operating the FT-ICR mass spectrometer.

1 Survey scan: in ICR cell (resolution 100,000, AGC target $=5 \times 10^{5}, 1 \mu \mathrm{Scan}$ )

2 MS $^{2}$ scans (five repeats): in linear ion trap (AGC target 10,000), isolation width of precursor 4 Da, excitation: 35 normalized collision energy for $30 \mathrm{~ms}$, with multistage activation on neutral loss peaks of precursor mass -32.659 and $-48.98840 \mathrm{Da}$

3 Single-charged ions were excluded for $\mathrm{MS}^{2}$ experiments

4 Masses used for $\mathrm{MS}^{2}$ experiments were excluded (in a range of $5 \mathrm{ppm}$ ) for further fragmentation for $60 \mathrm{~s}$

5 Ionizing spray voltage: $1.5 \mathrm{kV}$

The settings for the mass spectrometer were evaluated through a number of experiments (data not shown) to enable proper detection and fragmentation of the phosphorylated peptides.

a final volume of $50 \mathrm{ml}$ and a $\mathrm{pH} 10.5$. The buffer should not be older than 2 days.

Trypsin digestion buffer Dissolve $100 \mu \mathrm{g}$ trypsin ("Gold" from Promega) in $1 \mathrm{ml}(50 \mathrm{mM}) \mathrm{AA}$ to a final concentration of $100 \mathrm{ng} \mu \mathrm{l}^{-1}$. $\Delta$ CRITICAL Trypsin aliquots should be stored at $-80{ }^{\circ} \mathrm{C}$.

Chymotrypsin digestion buffer Dissolve $25 \mu \mathrm{g}$ chymotrypsin (sequencing grade from Roche) in $250 \mu \mathrm{l}$ of $1 \mathrm{mM} \mathrm{HCl}$ to a final concentration of $100 \mathrm{ng}^{\mathrm{N}} \mathrm{l}^{-1}$. $\triangle$ CRITICAL Chymotrypsin aliquots should be stored at $-80^{\circ} \mathrm{C}$.

Subtilisin digestion buffer Prepare a solution of $1 \mathrm{mg} \mathrm{ml}^{-1}$ subtilisin (Fluka) in $1 \mathrm{mM} \mathrm{HCl}$ and dilute it with $6 \mathrm{M}$ urea and $1 \mathrm{M}$ Tris by a factor of 1:50 to a final concentration of $20 \mathrm{ng} \mathrm{ml}^{-1}$.

DTT Dissolve $1 \mathrm{mg}$ of DTT in $2 \mathrm{ml}$ of $50 \mathrm{mM} \mathrm{ABC}$ buffer (pH 8.3).

$\triangle$ CRITICAL DTT must be prepared fresh before every digestion.

IAA Dissolve $5 \mathrm{mg}$ IAA in $2 \mathrm{ml}$ of $50 \mathrm{mM}$ ABC buffer (pH 8.3). $\triangle$ CRITICAL

IAA must be prepared fresh before every digestion.

HeLa culture medium High glucose Dulbecco's modified Eagle's medium supplemented with $10 \%(\mathrm{v} / \mathrm{v})$ fetal bovine serum (PAA Laboratories $\mathrm{GmbH}$ ), $0.3 \mu \mathrm{g} \mathrm{ml}^{-1}$ L-glutamine (Sigma-Aldrich), $100 \mathrm{U} \mathrm{ml}^{-1}$ penicillin (SigmaAldrich) and $100 \mu \mathrm{g} \mathrm{ml}^{-1}$ streptomycin (Sigma-Aldrich)

\section{EQUIPMENT SETUP}

HPLC system Chromatographic system: UltiMate Plus Nano-LC system (used for method development).

UltiMate 3000 Dual-gradient Nano-LC system (used for biological sample measurement). Both systems are from LC Packings-A Dionex Co. Injection system: FAMOS $\mu$-autosampler equipped with a $250 \mu \mathrm{l}$ sample loop, a user-defined injection method was used, LC Packings-

A Dionex Co.

HPLC detection system: UltiMate Plus UV Detector, $3 \mathrm{nl}$ flow cell, 214-nm detection wavelength.

MS: Thermo Finnigan LCQ DECA XP mass spectrometer (used for method development). Thermo Finnigan LTQ-Fourier Transform Ion Cyclotron Resonance mass spectrometer (used for measurement of biological sample).

Separation column: PepMap C18, $75 \mu \mathrm{m}$ ID $\times 150 \mathrm{~mm}$ length, $3 \mu \mathrm{m}$ particle size, 100 A pore size, LC Packings-A Dionex Co.

Trap (guard) columns: PepMap C18, $300 \mu \mathrm{m}$ ID $\times 5$ mm length, $3 \mu \mathrm{m}$ particle size, $100 \AA$ pore size, LC Packings-A Dionex Co.

Mobile phase A for RP column: 95\% water; $5 \%$ ACN; 0.1\% FA.

Mobile phase B for RP column: $20 \%$ water; $80 \%$ ACN; $0.1 \%$ FA.

Loading solvent for HPLC: water; $0.1 \%$ TFA

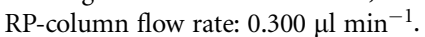

RP gradient for method testing This is shown in Table 3. The sample is loaded for 45 min onto an RP trap column (which is not online with the separation column) at a flow rate of $20 \mu \mathrm{min}^{-1}$ and washed free of ion-pairing agents, basic elution agent and other impurities. The gradient described starts at $45 \mathrm{~min}$ (the trap column is switched online with the separation column) and continues for $30 \mathrm{~min}$. After applying a high organic wash step (95\% mobile phase B), the trap column is switched back to offline mode and equilibrated with the loading mobile phase ${ }^{15}$. The MS data are recorded only for the time when both columns are online.
RP gradient for separation of the complex biological sample This is shown in Table 4. The sample is loaded for 40 min onto an RP trap column (which is not online with the separation column) at a flow rate of $20 \mu \mathrm{min}^{-1}$ and is washed free of ion-pairing agents, basic elution agent, IAA and DTT used in the digestion step and other impurities. Owing to a higher complexity of the sample and the presence of many highly abundant peptides, which often mask the low-abundant peptides, the gradient is significantly different in comparison to the gradient used for method tests and separation of less complex samples.

The gradient described starts at $38 \mathrm{~min}$ (the trap column is switched online with the separation column) and continues for $120 \mathrm{~min}$ with a very shallow increase to $25 \%$ B. The majority of peptides will elute on an RP column (under given conditions) at 20-35\% B (16.5-31.5\% ACN). By slowly increasing the amount of mobile phase B in the gradient, a better separation of coeluting peptides is possible. Finally, this approach results in a more sensitive detection in MS. After applying a high organic wash step (95\% mobile phase B), the trap column is switched back to offline mode and equilibrated with the loading mobile phase ${ }^{15}$. The MS data are recorded only for the time when both columns are online.

The method used for analysis of the simple test mixture was intentionally kept shorter for reasons of time saving and faster separation. However, the analysis of complex biological samples requires shallower gradients and longer wash times after the sample loading.

All chromatographic data have been acquired using Chromeleon HPLC software from Dionex.

MS equipment and settings for analyzing standard samples and method test Thermo Finnigan-LCQ DECA XP operated in positive nano-ESI mode. Ionizing spray voltage: $1.5 \mathrm{kV}$

Enhanced MS full-scan range: 220-2,000 amu

MS equipment and settings for analyzing the biological sample:

Thermo Finnigan-LTQ Fourier Transform mass spectrometer operated in positive nano-ESI mode using the settings described in Table 2.

Full scan was conducted in the ICR cell, yielding a survey scan with a resolution of 100,000 and a typical mass accuracy $<2$ ppm (rms); detection of the CAD fragment spectra $\left(\mathrm{MS}^{2}\right)$ was carried out in the linear ion trap. Using this method, the advantages of a highly accurate precursor mass and the high scan speed and low duty cycle time, respectively, for $\mathrm{MS}^{2}$ spectra were combined.

\section{Mascot search parameters}

Type of search

Fixed modifications

Variable modifications

Phospho_no_P-NL (STY)

Mass values

Protein mass

Peptide mass tolerance

Fragment mass tolerance

Max. missed cleavages
MS/MS Ion Search

Carbamidomethyl (C)

Oxidation (M)

Monoisotopic

Unrestricted

$\pm 5 \mathrm{ppm}$

$\pm 0.6 \mathrm{Da}$

3 


\section{PROCEDURE}

\section{Preparation of HeLa cell lysates}

1) Grow adherent HeLa cells in $145-\mathrm{mm}$ tissue culture dishes at $37{ }^{\circ} \mathrm{C}$ in the presence of $5 \% \mathrm{CO}_{2}$ in HeLa culture medium.

TABLE 3 | Gradient used for method tests and separation of less complex sample of BSA and synthetic phosphopeptides.

\begin{tabular}{llc}
\hline Time (min) & Mobile phase A (\%) & Mobile phase B (\%) \\
\hline $0-45$ & 100 & 0 \\
$45-74$ & $100-50$ & $0-50$ \\
$74-75$ & $50-5$ & $50-95$ \\
$75-80$ & 5 & 95 \\
$80-83$ & $5-100$ & $95-0$ \\
$83-100$ & 100 & 0 \\
\hline
\end{tabular}

TABLE 4 | Gradient used for separation of a complex biological sample.

\begin{tabular}{lcc}
\hline Time (min) & Mobile phase A (\%) & Mobile phase B (\%) \\
\hline $0-50$ & 100 & 0 \\
$50-178$ & $100-75$ & $0-25$ \\
$178-238$ & $75-50$ & $25-50$ \\
$239-267$ & 5 & 95 \\
268 & 100 & 0 \\
\hline
\end{tabular}

2| To arrest logarithmically proliferating cells in mitosis, plate at $6 \times 10^{6}$ for $4-6 \mathrm{~h}$ for attachment. Then, treat them at $60-80 \%$ confluency for $16 \mathrm{~h}$ with $330 \mathrm{nM}$ nocodazole.

3| Harvest the cells by scraping with a rubber policeman and by subsequent centrifugation at $\sim 260 \mathrm{~g}$ for 5 min at $4^{\circ} \mathrm{C}$ in a Biofuge. The cells need no treatment before removal. Wash the cell pellets twice with ice-cold PBS.

4| Resuspend the pellet obtained from 20 dishes (approximately $1 \mathrm{ml}$ containing $2 \times 10^{8}$ cells) (there is no minimum cell number for making extracts, but this is the amount required to perform this kind of MS analysis) in one volume $(\sim 1 \mathrm{ml})$ of ice-cold extraction buffer and homogenize in a pre-chilled Potter-Elvejhem glass-Teflon homogenizer.

5| To remove the bulk of cell debris and chromatin, centrifuge the lysates at $100,000 \mathrm{~g}$ and $4^{\circ} \mathrm{C}$ for 20 min in a Beckman Optima MAX ultracentrifuge using a Beckman TLA 45 rotor (42,000 rpm).

\section{Protein purification}

6| Immunopurify the APC from extracts of nocodazole-arrested HeLa cells (approximately $25 \mathrm{mg} \mathrm{ml}^{-1}$ ) using Cdc27 peptide antibodies crosslinked to Affi-Prep protein A beads as described previously ${ }^{13,14,22}$.

7| For MS analysis, wash the APC immunoprecipitates five times with 20 volumes of TBS-T0.01 buffer on a rotary shaker for 5 min at $4{ }^{\circ} \mathrm{C}$ and subsequently three times with 20 volumes of TBS.

8| Elute the APC-bound antibody beads by resuspending in 1.5 bead volumes of $100 \mathrm{mM}$ glycine-HCl, pH 2.2.

9| Rebuffer the sample by adding $1.5 \mathrm{M}$ Tris- $\mathrm{HCl}, \mathrm{pH} 9.2$, to suspension until $\mathrm{pH}$ is approximately 8 . Measurement with $\mathrm{pH}$

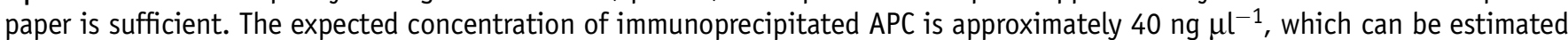
by comparison of a BSA dilution series to the APC dilution series on silver-stained SDS-PAGE.

\section{Sample digestion}

10| Reduce $100 \mu \mathrm{l}$ of sample (in our case, immunopurified APC isolated from about $10 \mathrm{mg}$ of total HeLa protein) by incubation with $1 \mu \mathrm{g}$ of DTT for $1 \mathrm{~h}$ at $37^{\circ} \mathrm{C}$.

11 After reduction, alkylate the sample by incubation with $5 \mu \mathrm{g}$ of iodoacetamide for $30 \mathrm{~min}$ at room temperature $\left(25^{\circ} \mathrm{C}\right)$ in the dark.

12| Digest the proteins in solution with one of the following proteases: $200 \mathrm{ng}$ ( $2 \mu \mathrm{l}$ of the prepared digestion buffer) of trypsin at $37{ }^{\circ} \mathrm{C}$ overnight, $200 \mathrm{ng}\left(2 \mu \mathrm{l}\right.$ of the prepared digestion buffer) of chymotrypsin (Fluka) for $5 \mathrm{~h}$ at $25^{\circ} \mathrm{C}$ or $800 \mathrm{ng}$ ( $40 \mu \mathrm{l}$ of the prepared digestion buffer) of subtilisin for $1 \mathrm{~h}$ at $37^{\circ} \mathrm{C}$.

13| Stop every digest with $1 \mu$ l of concentrated TFA.

14| Lyophilize the digested sample over a few hours almost to dryness. A volume of approximately $10 \mu \mathrm{l}$ should remain. If it accidentally becomes dry, treat it as usual but be aware of sample loss. 
PROTOCOL

\section{Phosphopeptide enrichment on titanium oxide trap column}

15| Prepare the load and wash solutions. See details in the REAGENTS section.

16| Dissolve the sample (in our case of method development: $500 \mathrm{fmol}$ BSA tryptic digest and $50 \mathrm{fmol}$ of synthetic phosphopeptides, or any other complex sample) in loading solvent to a total volume of $50 \mu$ l. Wash the TopTip by pipetting $20 \mu \mathrm{l}$ of wash solution onto the material and applying pressure using a pipette or a syringe. Discard the flow-through. Repeat this step twice.

17| Equilibrate the material by applying $3 \times 20 \mu$ l of loading solvent. Discard the flow-through.

18 Load the column by applying $2 \times 25 \mu \mathrm{l}$ of the sample. After each load, wait for $2 \mathrm{~min}$ to allow the sample to bind to $\mathrm{TiO}_{2}$. Collect the whole flow-through in a $0.2 \mathrm{ml}$ vial (labeled "Flow-through") for further analysis.

$\triangle$ CRITICAL STEP Use very gentle pressure to load the sample (=1 drop per $30 \mathrm{~s}$ ).

19| Wash the column by applying $2 \times 25 \mu$ l of the wash solution. Collect the whole flow-through in a $0.2 \mathrm{ml}$ vial (labeled "Wash") for further analysis. Keep the column wet throughout the complete procedure.

20| Elute the sample from the column by applying $3 \times 13.3 \mu$ l of elution buffer onto the column. Wait for at least 5 min after each elution step to allow proper absorption of solvents.

$\Delta$ CRITICAL STEP Use very gentle pressure to elute the sample $=1$ drop per $30 \mathrm{~s}$.

21| Collect the whole eluate in a $0.2 \mathrm{ml}$ vial (labeled "Eluate") for further analysis.

22| Cool the eluate on ice or in a fridge for acidification afterwards. Do not freeze it and do not wait for more than $1 \mathrm{~h}$ to acidify the sample.

23 While cooling the sample, apply $3 \times 20 \mu \mathrm{l}$ of wash solution to the TopTip for proper storage. The tips should be stored in a sealed bag and kept free of dust.

24| Acidify the eluate by adding $10 \mu \mathrm{l}$ of concentrated TFA to neutralize the $\mathrm{ABC}$ buffer and enable direct injection onto the nano HPLC system for further analysis (HPLC-MS/MS).

! CAUTION Pay attention when handling concentrated TFA. Heat and gas development can occur.

- PAUSE POINT The former sample is now separated into three $50 \mu$ fractions, "Flow-through", "Wash" and "Eluate", ready to perform further experiments or to be stored at $-80^{\circ} \mathrm{C}$.

\section{HPLC-MS/MS analysis of the prepared sample}

25 Inject the acidified sample onto the RP trap column and wash with $0.1 \%$ TFA for $50 \mathrm{~min}$. This will remove the phosphate buffer originating from elution and other impurities. The sample itself will bind to the RP trap column ${ }^{15}$. The sample is injected by using the "user-defined injection protocol-UDP": (i) Aspirate $16 \mu \mathrm{l}$ of transport liquid into the injection needle (needle volume $=15 \mu \mathrm{l}$ ). The injection valve of the autosampler is in the "Inject" position. (ii) The injection valve switches to the "Load" position and $50 \mu \mathrm{l}$ of sample is aspirated. (c) Aspirate an additional $16 \mu \mathrm{l}$ of transport liquid to transport the complete sample from the needle into the sample loop. (d) The injection valve switches to "Inject" position and the sample is transported to the RP trap column.

26| Elute the sample from the trap column onto the separation nano column and detect with a mass spectrometer. Use the gradient described in Table 4 for complex samples. See the EQUIPMENT section for MS settings.

\section{TIMING}

Preparation of HeLa cell lysates: depending on the amount to be harvested, this step needs up to 2 days

Protein purification:

Immunopurification, 90 min

Wash, $60 \mathrm{~min}$

Elution, $30 \mathrm{~min}$

Sample digestion:

Step 10, $60 \mathrm{~min}$

Step 11, $30 \mathrm{~min}$

Step 12, Between 1 and $5 \mathrm{~h}$ (depends on protease used for digestion)

Phosphopeptide enrichment on titanium oxide trap column:

Steps 14-17, $20 \mathrm{~min}$

Steps 18-21, $30 \mathrm{~min}$

Steps 22-24, $10 \mathrm{~min}$ 


\section{? TROUBLESHOOTING}

Troubleshooting advice can be found in Tables 5 and 6.

TABLE 5 | Troubleshooting table.

\begin{tabular}{|c|c|c|}
\hline Problem & Possible reason & Solution \\
\hline $\begin{array}{l}\text { Air bubbles running } \\
\text { through the titanium oxide } \\
\text { trap column bed }\end{array}$ & $\begin{array}{l}\text { Solvent was not applied directly onto } \\
\text { the bed }\end{array}$ & $\begin{array}{l}\text { Experiments showed that one need not worry about air bubbles } \\
\text { running through the bed, but they can be avoided: do not elute all of } \\
\text { the prior-applied solvent but keep a small volume of supernatant } \\
\text { before applying the next solvent volume. This will keep the column } \\
\text { free of air bubbles }\end{array}$ \\
\hline $\begin{array}{l}\text { Titanium oxide trap column } \\
\text { bed is interspersed with air } \\
\text { bubbles }\end{array}$ & $\begin{array}{l}\text { Most of the times this problem occurs if } \\
\text { the samples or solvents react, accompanied } \\
\text { by gas formation, for example, use of } \\
\text { bicarbonates with an acidic reagent }\end{array}$ & $\begin{array}{l}\text { Avoid the use of such solvents, or prevent them coming into } \\
\text { contact by washing the column with neutral solvents between } \\
\text { the two reagents }\end{array}$ \\
\hline $\begin{array}{l}\text { Contamination owing to } \\
\text { electrostatic attraction }\end{array}$ & $\begin{array}{l}\text { Owing to electrostatic attraction, the } \\
\text { column and vials are often littered with } \\
\text { dust and other small particles }\end{array}$ & $\begin{array}{l}\text { Work in a hood, or if not available, protect the vial opening with } \\
\text { Parafilm and puncture it with the column. This is also helpful for } \\
\text { fixing the column inside the vial }\end{array}$ \\
\hline
\end{tabular}

TABLE 6 | Recovery of synthetic phosphorylated peptides obtained by using different ion-pairing agents for peptide trapping.

\begin{tabular}{|c|c|c|c|}
\hline & $\begin{array}{l}20 \% \text { ACOH, } \\
300 \text { mM OSA (\%) }\end{array}$ & $\begin{array}{l}80 \% \text { ACN, } 0.1 \% \text { TFA, } \\
20 \mathrm{mg} \mathrm{ml}^{-1} \text { DHB (\%) }\end{array}$ & $\begin{array}{l}20 \% \text { AcOH, } 300 \mathrm{mM} \text { OSA, } \\
20 \mathrm{mg} \mathrm{ml}^{-1} \text { DHB (\%) }\end{array}$ \\
\hline PP7 & 100 & 100 & 72 \\
\hline PP3 & 57 & 100 & 87 \\
\hline PP8_ox & 97 & 74 & 100 \\
\hline PP5 & 78 & 88 & 56 \\
\hline PP1 & 100 & 100 & 100 \\
\hline PP4 & 100 & 100 & 80 \\
\hline PP2 & 87 & 100 & 75 \\
\hline PP9 & 74 & 58 & 62 \\
\hline PP10 & 42 & 33 & 47 \\
\hline NP6 & 4 & 100 & 0 \\
\hline GluFib & 30 & 94 & 9 \\
\hline
\end{tabular}

ACN, acetonitrile; DHB, 2,5-dihydroxybenzoic acid; OSA, 1-octanesulfonic acid; TFA, trifluoroacetic acid. By combining OSA and DHB, we were able to reduce the loss of phosphopeptides during the loading process.

\section{ANTICIPATED RESULTS}

To evaluate the utility of our $\mathrm{TiO}_{2}$-chemo-affinity chromatography technique for phosphopeptide enrichment and to optimize procedural conditions, the method was performed on peptide and phosphopeptide samples of different complexities and origins, and the resulting product peptides were analyzed by LC-MS/MS. First, to test the selectivity of the $\mathrm{TiO}_{2}$ column for phosphopeptides, a mix of synthetic phosphorylated and nonphosphorylated peptides was subjected to the method. Non-phosphorylated peptides failed to bind the $\mathrm{TiO}_{2}$ column, being detected in the flow-through or wash fractions (Fig. 1), whereas all the phosphopeptides bound the column and were

\footnotetext{
Figure 1 | Purification of phosphopeptides by $\mathrm{TiO}_{2}$ chemo-affinity chromatography. Shown are typical reversed-phase high-performance liquid chromatography base-peak chromatograms after treating the above-described standard peptide mix (500 fmol injected) with $\mathrm{TiO}_{2}$-packed pipette tips are shown. (a) Flow-through, showing the two non-phosphorylated peptides that were not retained; (b) wash fraction, showing no phosphopeptides eluting during the wash procedure; (c) phosphopeptides eluted from the $\mathrm{TiO}_{2}$-packed tip column using $125 \mathrm{mM} \mathrm{ABC}$ and $50 \mathrm{mM}$ ammonium phosphate at $\mathrm{pH} 10.5$.
}

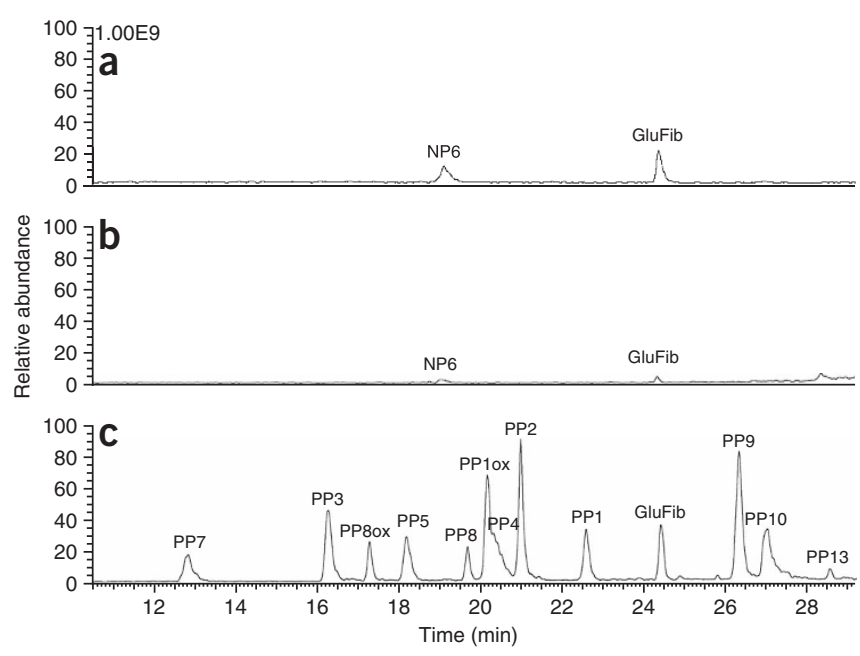


Figure 2 | Selectivity of $\mathrm{TiO}_{2}$ towards phosphopeptides. A sample containing $500 \mathrm{fmol}$ BSA spiked with $500 \mathrm{fmol}$ phosphopeptide mix was subjected to $\mathrm{TiO}_{2}$ chemo-affinity chromatography as described. Reversed-phase highperformance liquid chromatography base-peak chromatograms are shown. (a) The flow-through fraction contained the two non-phosphorylated synthetic peptides accompanied by some BSA peptides; (b) phosphopeptides eluted in a fraction after treating the $\mathrm{TiO}_{2}$ column with $125 \mathrm{mM} \mathrm{ABC}$ and $50 \mathrm{mM}$ ammonium phosphate at $\mathrm{pH} 10.5$.

successfully eluted. To test whether acidic peptides could also bind the $\mathrm{TiO}_{2}$ column and affect its selectivity for phosphopeptides, the peptide mix was supplemented with BSA-derived tryptic peptides. Here, the BSA peptides were found in both the flow-through and the eluate (Fig. 2), indicating that some non-phosphorylated peptides can also bind the $\mathrm{TiO}_{2}$ column, but they failed to prevent selective enrichment of the phosphopeptides. Although some BSA peptides were present at higher concentrations compared to synthetic phosphopeptides, a reduction in complexity of the sample is clearly demonstrated.

Peak area comparison of peptides before and after $\mathrm{TiO}_{2}$ enrichment (Fig. 3 ) showed a high percentage recovery of phosphopeptides at around $80-100 \%$, whereas the recovery for non-phosphorylated peptides was significantly lower. Upon elution with basic $A B C$ solution, the two non-phosphorylated peptides ("NP6" and "GluFib") appeared with a recovery below 2 and 10\%, respectively. This example shows that the binding of acidic non-phosphorylated peptides can be successfully inhibited. Regarding the recovery of PP1, its oxidized form has to be taken into account, and PP8 is present in an oxidized form only under current separation conditions.

Combining OSA and DHB resulted in a more effective removal of non-phosphorylated peptides. For example, the non-phosphorylated peptide NP6 was always present in the eluate when DHB was used. A significantly lower amount of NP6 was observed with OSA alone, and none was found when both agents were combined. For GluFib, the amount detected after basic elution was $<10 \%$, with $300 \mathrm{mM}$ OSA $\sim 30 \%$ and with $20 \mathrm{mg} \mathrm{ml}^{-1} \mathrm{DHB}>90 \%$. The results demonstrate that the combination of both agents led to high sequence coverage and reduced the binding of non-phosphorylated peptides. The non-phosphorylated peptides "NP6" and "Glufib" were successfully used as a negative control.

It was mentioned earlier that BSA peptides bound to the $\mathrm{TiO}_{2}$ column in all three cases: when using OSA, DHB or a combination of both agents. The combination of these ion-pairing agents lowered the amount of BSA peptides (calculated as areas of peptides found) in comparison to amounts when each agent was used alone. Table 7 shows data obtained by analyzing the mass spectra acquired with different loading solvents. We were able to reduce the number of peptides bound to the $\mathrm{TiO}_{2}$ column. Intriguingly, the Mascot score (calculated with $-10 \log _{10}(P)$, where $P$ is the absolute probability that the observed match is a random event) and the sequence coverage (a percent value how much of a given sequence was obtained by sample analysis) did not decrease in the same manner. We assume that the combination of both agents neutralizes the acidic groups on non-phosphorylated peptides more effectively in comparison to the use of either agent alone.

The suitability of our method for the enrichment of phosphopeptides from complex samples was confirmed by processing and analyzing a mix of peptides of biological origin, in this case a proteolyzed sample of human APC, for which we identified several phosphorylation sites previously ${ }^{13,14} \cdot \mathrm{TiO}_{2}$ enrichment of APC-derived peptides enabled the identification of nine additional phosphorylation sites in this complex (Table 8).

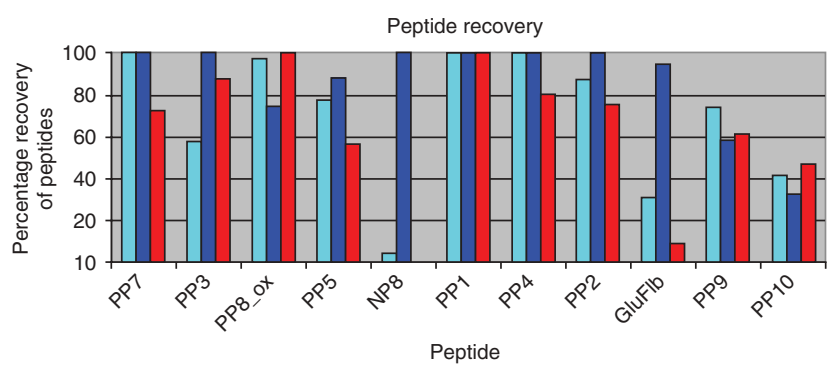

$\square 20 \% \mathrm{Ac} \mathrm{OH}, 300 \mathrm{mM}$ OSA $20 \% \mathrm{Ac} \mathrm{OH}, 300 \mathrm{mM}$ OSA, $20 \mathrm{mg} \mathrm{ml}^{-1} \mathrm{DHB}$
An example of an MS/MS spectrum for one novel phosphorylation site is shown in Figure 4, which shows the spectrum and corresponding fragment ion series of the additionally found phosphopeptide on the CDC26 subunit of the APC. Both $b$ - and $y$-ion series are almost complete and the NL of the $b(9)$ ion is visible in the spectrum. Similar results were obtained for other phosphopeptides identified.

Figure 3 | Recovery of phosphopeptides separated from a simulated complex mixture. Synthetic peptide mix ( $50 \mathrm{fmol}$ ) together with a tenfold excess of BSA (500 fmol) was purified using $\mathrm{TiO}_{2}$-packed tips as described, and the percentage recovery was determined by peak area comparison in selected ion monitoring. 
TABLE 7 | Sequence coverage, Mascot score and peptide count for the non-phosphorylated BSA peptides when trapped under different loading conditions.

\begin{tabular}{lccc}
\hline & \multicolumn{3}{c}{ Average } \\
\cline { 2 - 4 } & Sequence coverage (\%) & Score & Peptide found \\
\hline $20 \% \mathrm{AcOH}, 300 \mathrm{mM}$ OSA & 50 & 1,430 & 165 \\
$80 \% \mathrm{ACN}, 0.1 \%$ TFA, $20 \mathrm{mg} \mathrm{ml}^{-1} \mathrm{DHB}$ & 46 & 1,123 & 92 \\
$20 \% \mathrm{AcOH}, 300 \mathrm{mM} \mathrm{OSA}, 20 \mathrm{mg} \mathrm{ml}^{-1} \mathrm{DHB}$ & 42 & 1,105 & 70 \\
\hline
\end{tabular}

ACN, acetonitrile; DHB, 2,5-dihydroxybenzoic acid; 0SA, 1-octanesulfonic acid.

TABLE 8 | Additional phosphorylation sites found in APC.

\begin{tabular}{lllcccrrr}
\hline & Sequence & Protein & Mascot score & Mascot expect & Sequest Xc & Sequest Sf & Charge state & HPLC RT \\
\hline 1 & SSQFGSpLEF & CDC26 & 38 & 0.0024 & 3.47 & 0.93 & $2+$ & 108.63 \\
2 & EDVEVVGGSpDGEGAIGLSSDPK & CDC26 & 87 & $1 \mathrm{e}-07$ & 6.79 & 0.99 & $2+$ \\
3 & VGSpLQEVTIH & APC1 & 63 & 0.0017 & 4.60 & 0.97 & $2+$ \\
4 & VGSpLQEVTpIHEK & APC1 & 23 & 22 & 3.84 & 0.85 & $2+$ \\
5 & RVSpPLNLSSVTP & APC8 (CDC23) & 28 & 0.058 & 2.68 & 0.59 & $2+$ \\
6 & RVSpPLNLSSVTpP & APC8 (CDC23) & 31 & 0.03 & 3.35 & 0.86 & $2+$ \\
7 & QTAEETGLTPLETpSpR & APC6 (CDC16) & 37 & 0.01 & 3.74 & 0.72 & $2+$ \\
\hline
\end{tabular}

APC, anaphase-promoting complex. By employing the method described, it was possible to identify additional phosphorylation sites. The complete list of detected phosphopeptides will be published elsewhere. For the phospho-sites colored blue, their exact location cannot be distinguished.

The choice of correct "displacer" or ion-pairing agent for sample loading is one of the crucial steps for this technique. To effectively keep acidic and non-phosphorylated peptides away from binding to the $\mathrm{TiO}_{2}$ column, large amounts of ion-pairing agent must be added. We compared the previously described displacer, DHB, with an alternative, OSA, and the combination of both agents. When using DHB alone, disruption in phosphopeptide enrichment and massive interference in the MS signal occurred (data not shown), whereas this was not seen when using OSA alone or when OSA and DHB were combined for trapping of phosphopeptides.

Additionally, the method of generating of MS/MS spectra is very important for the quality of MS/MS spectra and the number of identified peptides. Therefore, we optimized not only the HPLC but also the MS methods used for detection. For proper analysis of phosphorylation sites, special fragmentation settings called MSA were used ${ }^{20,21}$. Compared to conventional ion dissociation, the MSA procedure increases both the number of fragments and their intensity. However, many of these ions with increased intensity or the newly produced ones had already experienced an NL of phosphoric acid. The phosphoric acid NL alone does not contribute to peptide sequence identification. The software recognizes the ions that experienced NL of phosphoric acid and activates them for further fragmentation. By this approach, the phosphorylated peptides can be distinguished from their non-phosphorylated counterparts and additionally fragmented. The additional fragmentation improves the quality of MS/MS spectra and leads to higher confidence scores for phosphorylated

peptides.

\section{Data analysis and peptide spectrum interpretation}

MS/MS spectra (dta file format) were extracted from the raw data using the BioWorks 3.2 software suite.

For Mascot database searches, dta files were merged using the perl script program merge.pl (Matrix science) into a single file (mgf file format).

Data were searched against the IPI human database v. 3.17 (ref. 18) with an MS accuracy of 7 ppm and an MS/MS accuracy of $0.6 \mathrm{Da}$.

For Sequest database searches, MS/MS spectra were analyzed by TurboSEQUEST, part of BioWorks 3.2 software, against the IPI human database with an MS accuracy of $7 \mathrm{ppm}$ and an MS/MS accuracy of $1.0 \mathrm{Da}$.

To confirm the results obtained with previous searches, a search against a randomized database combined with a normal IPI human database was performed ${ }^{19}$. The randomized database was generated with a program perl script decoy.pl, which is freely available from Matrix Science. Afterwards, the real and decoy databases were concatenated. A false-positive hit is given only when the match from the decoy sequence is better than the match from the correct sequence. Searching a reversed or randomized database is an excellent validation method for MS/MS searches of large data sets or for post-translational modifications. 
PROTOCOL

a

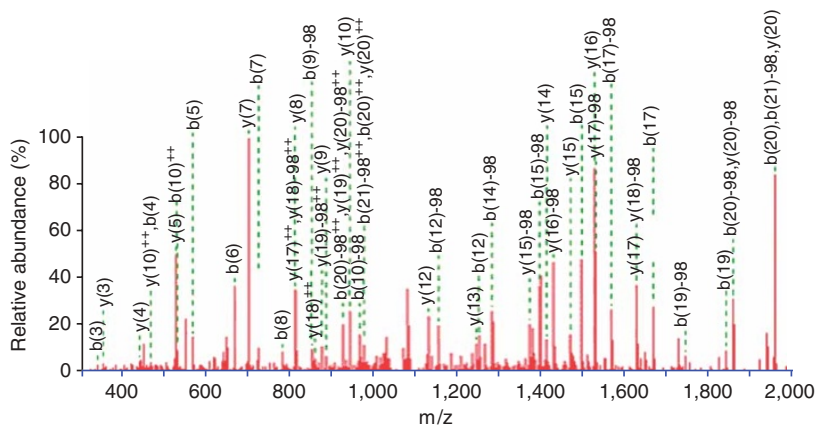

b

\begin{tabular}{|c|c|c|c|c|c|}
\hline No. & $b$ & $b^{++}$ & Seq. & $y$ & $y^{++}$ \\
\hline 1 & 130.04987 & 65.52857 & E & & \\
\hline 2 & 245.07681 & 123.04204 & D & 1969.93484 & 985.47106 \\
\hline 3 & 344.14522 & 172.57625 & v & 1854.90790 & 927.95759 \\
\hline 4 & 473.18781 & 237.09754 & E & 1755.83949 & 878.42338 \\
\hline 5 & 572.25622 & 286.63175 & v & 1629.79690 & 813.90209 \\
\hline 6 & 671.32463 & 336.16595 & v & 1527.72849 & 764.36788 \\
\hline 7 & 728.34609 & 364.67668 & G & 1428.66008 & 714.83368 \\
\hline 8 & 785.36755 & 393.18741 & G & 1371.63862 & 686.32295 \\
\hline 9 & 854.38900 & 427.69814 & S & 1314.61716 & 657.81222 \\
\hline 10 & 969.41594 & 485.21161 & D & 1245.59570 & 623.30149 \\
\hline 11 & 1026.43740 & 513.72234 & G & 1130.56876 & 565.78802 \\
\hline
\end{tabular}

\begin{tabular}{|l|l|l|l|l|l|l|}
\hline No. b & beq. $y$ & $y^{++}$ & No. \\
\hline 12 & 1155.47999 & 578.24364 E & 1073.54730 & 537.27729 & 11 \\
\hline 13 & 1212.50145 & 606.75437 & G & 944.50471 & 472.75599 & 10 \\
\hline 14 & 1283.53856 & 642.27292 & A & 887.48325 & 444.24526 & 9 \\
\hline 15 & 1396.62262 & 698.81495 & I & 816.44614 & 408.72671 & 8 \\
\hline 16 & 1453.64408 & 727.32568 & $G$ & 703.36208 & 352.18468 & 7 \\
\hline 17 & 1566.72814 & 783.86771 & L & 646.34062 & 323.67395 & 6 \\
\hline 18 & 1653.76017 & 827.38372 & S & 533.25656 & 267.13192 & 5 \\
\hline 19 & 1740.79220 & 870.89974 & S & 446.22453 & 223.61590 & 4 \\
\hline 20 & 1855.81914 & 928.41321 & D & 359.19250 & 180.09989 & 3 \\
\hline 21 & 1952.87190 & 976.93959 & P & 244.16556 & 122.58642 & 2 \\
\hline 22 & & & K & 147.11280 & 74.06004 & 1 \\
\hline
\end{tabular}

Figure 4 | Identification of a novel APC-derived phosphorylation site. This shows the spectra (a) and corresponding product ion series (b) of the newly identified phosphopeptide in the digested APC sample. Ser42 was found on the CDC26 peptide EDVEVVGGSpDGEGAIGLSSDPK.

We anticipate that this method could be widely used to enrich phosphopeptides from protein samples from diverse biological origins, facilitating the identification of additional sites of phosphorylation in proteins of interest. This technology could contribute to further improving our understanding of cell-signaling pathways and could have application in large-scale phospho-proteomic studies.

ACKNOWLEDGMENTS We are grateful to Ines Steinmacher, Richard Imre, Michael Schutzbier and Otto Hudecz for their support in carrying out MS measurements and reviewing this manuscript. This work was supported by the Austrian Proteomics Platform (APP) within the Austrian Genome Research Programme (GEN-AU) and by the Mitocheck project within the Sixth Framework Program of the European Commission.

COMPETING INTERESTS STATEMENT The authors declare that they have no competing financial interests.

Published online at http://www.natureprotocols.com

Reprints and permissions information is available online at http://npg.nature.com/ reprintsandpermissions

1. McLachlin, D.T. \& Chait, B.T. Analysis of phosphorylated proteins and peptides by mass spectrometry. Curr. Opin. Chem. Biol. 5, 591-602 (2001).

2. Hubbard, M.J. \& Cohen, P. On target with a new mechanism for the regulation of protein phosphorylation. Trends Biochem. Sci. 18, 172-177 (1993).

3. Roepstorff, P. \& Kristiansen, K. Biomed. Mass Spectrom. 1, 231-236 (1974).

4. Graves, J.D. \& Krebs, E.G. Protein phosphorylation and signal transduction. Pharmacol. Ther. 82, 111-121 (1999).
5. Ficcaro, S.B. et al. Phosphoproteome analysis by mass spectrometry and its application to Saccharomyces cerevisiae. Nat. Biotechnol. 20, 301-305 (2002).

6. Kange, R. et al. Comparison of different IMAC techniques used for enrichment of phosphorylated peptides. J. Biomol. Tech. 16, 91-103 (2005).

7. Ballif, B.A., Villén, J., Beausoleil, S.A., Schwartz, D. \& Gygi, S.P. Phosphoproteomic analysis of the developing mouse brain. Mol. Cell Proteomics 3.11, 1093-1101 (2004).

8. Peng, J., Elias, J.E., Thoreen, C.C., Licklider, L.J. \& Gygi, S.P. Evaluation of multidimensional chromatography coupled with tandem mass spectrometry (LC/LC-MS/MS) for large-scale protein analysis: the yeast proteome. J. Proteome Res. 2, 43-50 (2003).

9. Gruhler, A. et al. Quantitative phosphoproteome applied to the yeast pheromone signaling pathway. Mol. Cell Proteomics 4.3, 310-327 (2005).

10. Beausoleil, S.S. et al. Large-scale characterization of HeLa cell nuclear phosphoproteins. Proc. Natl. Acad. Sci. USA 101, 12130-12135 (2004).

11. Larsen, M.R., Thingholm, T.E., Jensen, O.N., Roepstorff, P. \& Jorgensen, T.J. Highly selective enrichment of phosphorylated peptides from peptide mixtures using titanium dioxide microcolumns. Mol. Cell Proteomics 4, 873-886 (2005).

12. Pinkse, M., Uitto, P.M., Hilhorts, M.J., Ooms, B. \& Heck, A.J. Selective isolation at the femtomole level of phosphopeptides from proteolytic digests using 
2D-nanoLC-ESI-MS/MS and titanium dioxide precolumns. Anal. Chem. 76, 3935-3943 (2004).

13. Kraft, C. et al. Mitotic regulation of the human anaphase-promoting complex by phosphorylation. EMBO J. 22, 6598-6609 (2003).

14. Herzog, F., Mechtler, K. \& Peters, J.M. Identification of cell cycle-dependent phosphorylation sites on the anaphase-promoting complex/cyclosome by mass spectrometry. Methods Enzymol. 398, 231-245 (2005).

15. Mituloviæ, G. et al. An improved method for tracking and reducing the void volume in nano HPLC-MS with micro trapping columns. Anal. Bioanal. Chem. 376, 946-951 (2003).

16. Bennet, H.P.J. Manipulation of $\mathrm{pH}$ and ion-pairing reagents to maximize the performance of reversed-phase columns. in High-performance Liquid Chromatography of Peptides and Proteins: Separation Analysis, and Conformation (eds. Colin, T.M. \& Robert, S.H) 319-325 CRC Press, Boca Raton, FL 33431, USA (1991).

17. Mant, C.T \& Hodges, R.S. The effects of anionic ion-pairing reagents on peptide retention in reversed-phase chromatography. in High-performance Liquid
Chromatography of Peptides and Proteins: Separation, Analysis, and Conformation (eds. Colin, T.M \& Robert, S.H) 327-341 CRC Press, Boca Raton, FL 33431, USA (1991).

18. Kersey, P.J., Duarte, J., Williams, A., Karavidopoulou, Y. \& Birney, E. The International Protein Index: an integrated database for proteomics experiments. Proteomics 4, 1985-1988 (2004).

19. Elias, J.E., Haas, W., Faherty, B.K. \& Gygi, S.P. Comparative evaluation of mass spectrometry platforms used in large-scale proteomics investigations. Nat. Methods 2, 667-675 (2005).

20. Schroeder, M.J., Shabanowitz, J., Schwartz, J.C., Hunt, D.F. \& Coon, J.J. A neutral loss activation method for improved phosphopeptide sequence analysis by quadrupole ion trap mass spectrometer. Anal. Chem. 76, 3590-3598 (2004).

21. Zumwalt, A., Choudhary, G., Cho, D., Hemenway, E. \& Mylchreest, I. Proc. 51st ASMS Conf. Mass Spectrom. Allied Top. 2003.

22. Herzog, F. \& Peters, J.M. Large-scale purification of the vertebrate anaphasepromoting complex/cyclosome. Methods Enzymol. 398, 175-195 (2005). 


\section{Erratum: Titanium dioxide as a chemo-affinity solid phase in offline phosphopeptide chromatography prior to HPLC-MS/MS analysis}

Michael Mazanek, Goran Mituloviæ, Franz Herzog, Christoph Stingl, James RA Hutchins, Jan-Michael Peters \& Karl Mechtler

Nat. Protoc. 2, 1059-1069 (2007); published online 14 December 2006; corrected online 3 May 2007.

In the version initially published online, this article was listed as being in vol. 1, no. 4, and the page numbers were shown as 1977-1987. The corrected information is: vol. 2, no. 5, pp. 1059-1069. These errors have been corrected in all versions of the article. 